\title{
Perceptions of the interprofessional education of the faculty and the level of interprofessional education competence of the students perceived by the faculty: a comparative study of medicine, nursing, and pharmacy
}

\author{
So Jung Yune', Kwi Hwa Park', Yul Ha Min ${ }^{3}$ and Eunhee $\mathrm{Ji}^{4}$ \\ ${ }^{1}$ Department of Medical Education, Pusan National University College of Medicine, Busan, ${ }^{2}$ Department of Medical \\ Education, Gachon University College of Medicine, ${ }^{3}$ Gachon University College of Nursing, and ${ }^{4}$ Gachon University \\ College of Pharmacy, Incheon, Korea
}

Purpose: This study will compare differences in perception of interprofessional education (IPE) in the faculty of medicine, nursing, and pharmacy. It will also analyze differences in the level of importance of IPE competences and the present competence levels of their students perceived by the faculty.

Methods: The study included 115 participants from the faculty of medicine, 31 from nursing, and 23 from pharmacy. The surveys contained 21 questions on their perceptions of IPE, and perception on the nine competences of IPE. The results were analyzed using analysis of variance and $\chi^{2}$ analysis, and the Borich coefficient was calculated to identify the educational order of priority from the competence levels of their student of IPE.

Results: Participants of $14.8 \%$ responded that they were aware of IPE, $95.8 \%$ responded that they did not have experience in IPE, and $95.8 \%$ responded that IPE was necessary. Among the subfactors of perception of IPE, the faculty of medicine had significantly lower perceptions of the importance, effectiveness, and support of IPE $(p<0.001)$. The present competence levels of their students were significantly lower $(p<0.001)$ than the level of importance of IPE competences perceived by the faculty, and its perception was at its lowest in the faculty of medicine. The needs assessment of the IPE program was in the order of communication skills (10.210), conflict-solving skills (10.114), problem-solving skills (9.319), empathy skills (9.110), and collaborative leadership (8.624) among the nine competences.

Conclusion: This study will contribute to providing basic data needed to develop faculty development programs on IPE and IPE programs for their students.

Key Words: Medical education, Nursing education, Pharmacy education, Needs assessment

\section{Introduction}

In terms of the safety of patients, there has been a continuous emphasis on the importance of collaborative practice and communication among those in the health and medical fields. Due to the rapid changes in the healthcare environment, there are limitations on a single healthcare expert's ability to solve the health problems of a patient. Also, the perspective towards healthcare is
Received: January 13, 2020 • Revised: February 3, 2020 • Accepted: February 3, 2020 Corresponding Author: Kwi Hwa Park (https://orcid.org/0000-0002-0008-2400)

Department of Medical Education, Gachon University College of Medicine, 38-13 Dokjeom-ro 3beon-gil, Namdong-gu, Incheon 21565, Korea

Tel: +82.32.458.2635 Fax: +82.32.421.5537 email: ghpark@gachon.ac.kr
Korean J Med Educ 2020 Mar; 32(1): 23-33.

https://doi.org/10.3946/kjme.2020.150

eISSN: 2005-7288

(C) The Korean Society of Medical Education. All rights reserved. This is an open-access article distributed under the terms of the Creative Commons Attribution Non-Commercial License (http:// creativecommons.org/licenses/by-nc/3.0/), which permits unrestricted non-commercial use, distribution, and reproduction in any medium, provided the original work is properly cited. 
changing from the traditional perspective of "doctorpatient relationship" to "effective medical care teampatient relationship." In other words, there is an increased emphasis on the importance of a medical care team that can share professional knowledge and techniques and can make appropriate clinical decisions between them. Proper communication, through $\mathrm{Co}^{-}$ operation with medical care experts from other fields, leads to healthcare developments by increasing patients' treatment satisfaction, and decreasing medical errors and costs [1]. Therefore, there have been active discussions on interprofessional education (IPE), which refers to the collaborative practice among healthcare professionals, including doctors, nurses, dentists, and pharmacists with other professionals, to perform their tasks and develop their competences [2,3].

The purpose of IPE is to promote effective cooperation among healthcare experts and improve the quality of medical services by allowing students or professionals of the healthcare fields to learn together, learn from one another, and learn about one another [4]. In other words, the collaborative process of building relationships among students of the healthcare fields through IPE is an important factor that relates to the success of the medical team that they will be a part of in the future. The students will learn how to cooperate while learning with students from other fields through IPE and will develop competences to better understand and identify the perspectives of those from other fields.

IPE programs are already being developed after having been through various phases of trial and error in some European countries, as well as Canada and the United States. In the United Kingdom, the Center for the Advancement of Interprofessional Professional Education was established in 1987, and there are academic approaches in the area with related journals [4]. Canada started the Interprofessional Education for Collaborative
Patient-Centered Practice Initiative in 2003, and there have been active education programs in the United States such as the Interprofessional Education Collaborative, that has been active since 2009 between schools of medicine, nursing, dentistry, and pharmacy.

In other countries, collaborative practice between the various areas of the healthcare field is listed as an essential requirement of the accreditation of medical school, and there is an increase of IPE from the education curriculum of doctors, nurses, pharmacists, and social workers [5]. According to a study, 93\% of 16 universities incorporated IPE between the schools of medicine and nursing, and 57\% incorporated IPE with schools of pharmacy as well in the United States [6]. In addition, $66 \%$ of 48 medical schools in the United States provided either official or unofficial opportunities for students to experience other healthcare field [7]. There is also a growing importance for IPE not only in schools of medicine and nursing, but in schools of pharmacy as well. As the curriculum of the school of pharmacy was extended from 4 to 6 years, there has been greater emphasis on clinical pharmacy education as a way to develop pharmacists' clinical competences $[8,9]$.

However, IPE is an unfamiliar concept for the clinical environment of Korea. Eighty-six percent of doctors and $63 \%$ of nurses have no experience in IPE [10], and only $12 \%$ of nurses and the faculty of nursing know about IPE [11], which is extremely low in comparison to other countries $[12,13]$. However, most of the medical students do not receive opportunities to be exposed to IPE before going into clinical practice and have no awareness of its importance [14]. As such, even faculty members have little experience in IPE programs, and the students do not have enough opportunities to learn about IPE. In other words, there is a need for active efforts to implement and apply IPE programs in the healthcare fields in Korea. In order to implement and apply a new 
program in the medical education field, it is necessary to change the perception of faculty members and establish a faculty development program to set the directions for student education. In order to develop an IPE faculty development program, it is necessary to identify the faculty members' perception of IPE from the various healthcare and analyze the differences by areas of expertise. Furthermore, when setting the directions for IPE student education, faculty members should understand the present IPE competences of students to select the order of priority. This is because the difference between the level of importance for each competence, and the present level of competence is important when deciding the relative importance of the education and becomes the standard to select the order of priority [15]. From the perspective of the educator, if students' competence level is lower than the level of importance of IPE competences, it will be helpful to decide which parts need to be more focused on in student education. However, there are few studies that focus on the faculty members who should be responsible for developing and teaching the IPE programs in Korea or identify their perception of IPE and their perception of their students IPE competence levels. Moreover, it is difficult to find studies that have compared the differences between the faculty members of various fields of healthcare, such as medicine, nursing, and pharmacy.
Therefore, this study will compare and analyze the differences in the perception of IPE from faculty members of medicine, nursing, and pharmacy. Then, the study will analyze the differences of perception in the level of importance of each competence and the present competence levels of the students perceived by faculty. This study will add to the mutual understanding of IPE among professionals in the healthcare, and thus validate the implementation of IPE. Furthermore, it will contribute to providing the basic data needed to develop faculty development programs on IPE as well as student IPE programs.

\section{Methods}

\section{Sample}

The subjects are faculty members of the schools of medicine, nursing, and pharmacy from five universities. A total of 300 surveys were distributed, of which 169 (56.3\%) were returned. Of the participants, 115 were from the faculty of medical school, 31 were from the faculty of nursing, and 23 were from the faculty of pharmacy. Table 1 shows the gender, status, and age distribution of the faculty members.

\begin{tabular}{clcccc}
\hline \multicolumn{2}{l}{ Table 1. General Characteristics of Subjects $(N=169)$} & & & \\
\hline Characteristic & \multicolumn{1}{c}{ Category } & Medicine & Nursing & Pharmacy & Total \\
\hline Gender & Male & 92 & 0 & 8 & 100 \\
\multirow{3}{*}{ Position } & Female & 23 & 31 & 15 & 69 \\
& Professor & 35 & 10 & 5 & 50 \\
\multirow{3}{*}{ Age (yr) } & Associate professor & 27 & 9 & 5 & 41 \\
& Assistant professor & 53 & 12 & 13 & 78 \\
& 30s & 29 & 2 & 5 & 36 \\
Total & 40s & 61 & 16 & 10 & 87 \\
& 50s & 20 & 8 & 7 & 35 \\
& 60s & 5 & 5 & 1 & 11 \\
\end{tabular}




\section{Instrumentation}

\section{1) Survey on perceptions of interprofessional education}

The survey on perceptions of IPE consisted of three items: “Do you know about IPE?", "Have you had experiences with IPE?", and "Is IPE necessary?", 18 items on the survey asked about their perceptions of IPE; first, 20 items were developed based on research of the related literature [16,17] and the advice of three professionals in the medical education. However, the scale consisted of a total of 18 questions consisting of four factors according to the results of the factor analysis that was conducted for validity verification. The four subfactors on the importance of IPE (I, six items), participatory willingness of IPE (II, five items), effectiveness of IPE (III, five items), and support for IPE (IV, two items) accounted for $68.09 \%$ of the total variables. The reliability (Cronbach's $\alpha$ ) of all of the subfactors was satisfactory; the reliability of the importance of IPE was 0.858 , the participatory willingness of IPE was 0.881 , the effectiveness of IPE was 0.879, and support for IPE was 0.701 (Table 2). The responses to the items used a 5-point Likert

Table 2. Factor Loadings for IPE Perception of 18 Items

\begin{tabular}{|c|c|c|c|c|c|}
\hline \multirow{2}{*}{ Item } & \multicolumn{4}{|c|}{ Factor } & \multirow{2}{*}{ Cronbach $a$} \\
\hline & 1 & $\|$ & III & IV & \\
\hline $\begin{array}{l}\text { 3. Our students should have experiences in being taught by professors } \\
\text { of other healthcare field. }\end{array}$ & 0.769 & 0.180 & 0.187 & 0.087 & 0.858 \\
\hline $\begin{array}{l}\text { 4. It is necessary for our students to participate in lectures with students } \\
\text { in different healthcare field. }\end{array}$ & 0.724 & 0.197 & 0.259 & -0.039 & \\
\hline 2. IPE should be one of the educational goals of our department. & 0.691 & 0.210 & 0.110 & 0.231 & \\
\hline $\begin{array}{l}\text { 5. It is necessary for our students to participate in clinical practices with } \\
\text { students from other healthcare field. }\end{array}$ & 0.635 & 0.235 & 0.353 & 0.009 & \\
\hline $\begin{array}{l}\text { 1. It is important for our department to provide students with the } \\
\text { opportunities to participate in IPE. }\end{array}$ & 0.593 & 0.201 & 0.237 & 0.289 & \\
\hline $\begin{array}{l}\text { 6. IPE will improve collaborative practice among the students in various } \\
\text { field of the clinical environment. }\end{array}$ & 0.592 & 0.210 & 0.460 & 0.233 & \\
\hline $\begin{array}{l}\text { 13. I prefer providing shared lectures (for example, team teaching) with } \\
\text { professors of other healthcare field. }\end{array}$ & 0.276 & 0.810 & 0.126 & 0.025 & 0.881 \\
\hline 14. I am confident in teaching students of other healthcare field. & 0.048 & 0.806 & 0.166 & 0.130 & \\
\hline $\begin{array}{l}\text { 12. I prefer providing lectures to students in other healthcare field (example: } \\
\text { School of Medicine, School of Dentistry, School of Nursing). }\end{array}$ & 0.147 & 0.785 & 0.169 & -0.136 & \\
\hline $\begin{array}{l}\text { 16. I am willing to participate in faculty development programs related } \\
\text { to IPE within the field of healthcare. }\end{array}$ & 0.306 & 0.745 & 0.144 & 0.110 & \\
\hline $\begin{array}{l}\text { 15. It is advisory to recommend professors to participate in subjects related } \\
\text { to IPE. }\end{array}$ & 0.405 & 0.681 & 0.190 & 0.207 & \\
\hline 9. IPE is helpful for students to understand the medical care system. & 0.079 & 0.141 & 0.869 & 0.217 & 0.879 \\
\hline $\begin{array}{l}\text { 10. IPE is helpful for students to understand the roles and responsibilities } \\
\text { of those in other healthcare field within the medical care environment. }\end{array}$ & 0.243 & 0.203 & 0.831 & 0.118 & \\
\hline $\begin{array}{l}\text { 8. IPE is helpful for students to understand the limitations of their field } \\
\text { within the clinical environment. }\end{array}$ & 0.342 & 0.057 & 0.649 & 0.051 & \\
\hline $\begin{array}{l}\text { 7. IPE will improve communication among the students of various fields } \\
\text { within the clinical practices. }\end{array}$ & 0.475 & 0.317 & 0.641 & 0.172 & \\
\hline $\begin{array}{l}\text { 11. IPE allows for students to respect and trust students from other field } \\
\text { of healthcare. }\end{array}$ & 0.371 & 0.285 & 0.625 & 0.130 & \\
\hline 18. Professors should be awarded if they participate in IPE. & 0.132 & -0.080 & 0.147 & 0.838 & 0.701 \\
\hline 17. IPE needs the support of the related organizations of the school. & 0.173 & 0.226 & 0.211 & 0.796 & \\
\hline
\end{tabular}

Factor I: The importance of IPE, factor II: Participatory willingness of IPE, factor III: Effectiveness of IPE, factor IV: Support for IPE. IPE: Interprofessional education. 
scale (strongly disagree: 1 to strongly agree: 5).

2) Survey on common competency of interprofessional education

A survey was developed to identify the competences of students needed for IPE, and to select the order of education priority for the competency-based education curriculum. First, the competences were selected based on prior studies $[11,18]$, and a total of nine competences were selected after receiving advices from three professionals in the field of medical education. The nine competences are: collaborative leadership, communication skills, empathy skills, conflict solving skills, decision making skills, problem solving skills, understanding the roles of other professionals, understanding their own roles within the collaborative practice, and legal ethical decision-making skills. The respondents were asked to choose the level of importance and the present competence levels of their students.

\section{Procedure}

The authors of the study distributed surveys to the participants who were given explanations on the purpose of the study, anonymity, and confidentiality and agreed to participate in the study. The participants of the study who agreed to participate read and responded to the survey by themselves. We conducted survey with faculty of medicine, nursing, and pharmacy between April 1 and 20, 2018 in Korea.

\section{Ethical considerations}

This survey was ethically approved by the Gachon University Gil Medical Center Institutional Review Board (approval no., GCIRB-2018-150).

\section{Data analysis}

Data analysis used the following method. First, analysis of variance and $\chi^{2}$ test was conducted to examine the difference in perception of IPE among the faculty of medicine, nursing, and pharmacy. Second, the Borich coefficient for needs assessment was calculated to identify the educational order of priority from the competence levels of their student of IPE perceived by faculty (Borich's model $=\sum(\mathrm{RCL}-\mathrm{PCL}) \times \overline{\mathrm{RCL}} / \mathrm{N} ; \mathrm{RCL}$ : Required competence level, PCL: Present competence level, $\overline{\mathrm{RCL}}$ : The mean scores for required competence level, N: Total) [19]. The IBM SPSS ver. 23.0 (IBM Corp., Armonk, USA) was used for all statistical analysis.

\section{Results}

\section{Differences in the perception on inter- professional education of the faculty members}

Table 3 shows the results of the three items on the perception of IPE. For the item "Do you know about IPE?", $1(0.6 \%)$ responded "I know very well about IPE," 24 (14.2\%) responded "I know about IPE," 45 (26.6\%) answered "I have heard of IPE but I don't know about it," 53 (31.4\%) answered “I don't know IPE," and 46 (27.2\%) answered "I have no idea about IPE." There were significant differences among the faculty members in the schools of medicine, nursing, and pharmacy $\left(\chi^{2}=17.555\right.$, $\mathrm{p}=0.025)$. There were a significantly higher number of faculty members in the school of medicine who responded that they did not know about IPE.

For the item "Have you ever experienced IPE?", 7 (4.2\%) responded "yes" while 161 (95.8\%) responded "no." There were no significant differences among the faculty members in the schools of medicine, nursing, and pharmacy $\left(\chi^{2}=0.084, \mathrm{p}=0.959\right)$.

For the item "Do you think IPE is needed?", 29 (17.6\%) responded "highly necessary," 86 (52.1\%) responded 
Table 3. Differences in the Perception on IPE of the Faculty Members

\begin{tabular}{clcccccc}
\hline \multicolumn{1}{c}{ Item } & \multicolumn{1}{c}{ Category } & Medicine & Nursing & Pharmacy & total & $\chi^{2}$ & $p$-value \\
\hline Do you know about IPE? & Strongly agree & 0 & 0 & $1(4.3)$ & $1(0.6)$ & 17.555 & 0.025 \\
& Agree & $15(13.0)$ & $4(12.9)$ & $5(21.7)$ & $24(14.2)$ & & \\
& Neutral & $25(21.7)$ & $13(41.9)$ & $7(30.4)$ & $45(26.6)$ & & \\
& Disagree & $38(33.0)$ & $11(35.5)$ & $4(17.4)$ & $53(31.4)$ & & \\
& Strongly disagree & $37(32.3)$ & $3(9.7)$ & $6(26.2)$ & $46(27.2)$ & & \\
Have you ever experienced IPE? & Yes & $5(4.4)$ & $1(3.2)$ & $1(4.3)$ & $7(4.2)$ & 0.084 & 0.959 \\
& No & $109(95.6)$ & $30(96.8)$ & $22(95.7)$ & $161(95.8)$ & & \\
Do you think IPE is needed? & Strongly agree & $19(17.0)$ & $6(19.4)$ & $4(18.2)$ & $29(17.6)$ & 6.863 & 0.551 \\
& Agree & $53(47.3)$ & $21(67.7)$ & $12(54.5)$ & $86(52.1)$ & & \\
& Neutral & $34(30.4)$ & $4(12.9)$ & $5(22.7)$ & $43(26.1)$ & & \\
& Disagree & $5(4.5)$ & 0 & $1(4.5)$ & $6(3.6)$ & & \\
& Strongly disagree & $1(0.9)$ & 0 & $9(0)$ & $1(0.6)$ & & \\
\hline
\end{tabular}

Data are presented as number (\%).

IPE: Interprofessional education.

Table 4. Differences in Faculty Perceptions on Four Factors of IPE Scale

\begin{tabular}{lcccccc}
\hline \multicolumn{1}{c}{ Factor } & Medicine $^{1}$ & Nursing $^{2}$ & Pharmacy $^{3}$ & $F$ & p-value & Scheffé $^{\prime}$ \\
\hline The importance of IPE & $3.55 \pm 0.64$ & $3.99 \pm 0.58$ & $3.86 \pm 0.60$ & 7.302 & 0.001 & $1<2$ \\
Participatory willingness of IPE & $3.41 \pm 0.70$ & $3.58 \pm 0.69$ & $3.54 \pm 0.75$ & 0.945 & 0.391 & \\
Effectiveness of IPE & $3.82 \pm 0.57$ & $4.18 \pm 0.49$ & $4.21 \pm 0.64$ & 8.087 & 0.000 & $1<2,1<3$ \\
Support for IPE & $3.86 \pm 0.67$ & $4.26 \pm 0.60$ & $4.24 \pm 0.74$ & 6.365 & 0.002 & $1<2,1<3$ \\
\hline
\end{tabular}

Data are presented as mean \pm standard deviation, unless otherwise stated.

IPE: Interprofessional education.

"necessary," 43 (26.1\%) responded "slightly necessary," 6 (3.6\%) responded "not necessary," and $1(0.6 \%)$ responded "highly not necessary." There were no significant differences among the faculty members in the schools of medicine, nursing, and pharmacy $\left(\chi^{2}=6.863, p=0.551\right)$.

Also, we identified whether there were differences between the faculty members in the schools of medicine, nursing, and pharmacy in their perception of the importance of IPE, participatory willingness of IPE, effectiveness of IPE, and support for IPE (Table 4). The results showed that among the subfactors, there were significant differences between faculty members in the schools of medicine, nursing, and pharmacy on the perceptions of the importance of IPE $(F=7.302, p=0.001)$, effectiveness of IPE ( $\mathrm{F}=8.087, \mathrm{p}=0.000)$, and support for IPE ( $\mathrm{F}=6.365, \mathrm{p}=0.002)$. The faculty members in the school of medicine showed significantly lower perceptions.

\section{Differences in the level of importance of interprofessional education competences and the present competence levels of their students perceived by the faculty members}

The results of the analysis on the differences in the level of importance of IPE competences of the faculty members, and the present competence levels of their students showed significant differences in all competences $(\mathrm{p}=0.000)$. The present competence levels of their students were significantly lower than the level of importance of IPE competence levels when the result was classified into their majors of medicine, nursing, and pharmacy $(\mathrm{p}=0.000)$. Among the faculty members in the schools of medicine, nursing, and pharmacy, those from the school of medicine had the lowest perceptions of the levels of their students, as 
Table 5. Differences in the Level of Importance of Interprofessional Education Competences and the Present Competence Levels of Their Students Perceived by the Faculty Members

\begin{tabular}{|c|c|c|c|c|c|c|c|c|c|c|c|c|}
\hline \multirow{2}{*}{ Competence } & \multicolumn{3}{|c|}{ Medicine } & \multicolumn{3}{|c|}{ Nursing } & \multicolumn{3}{|c|}{ Pharmacy } & \multicolumn{3}{|c|}{ Total } \\
\hline & $A$ & $B$ & t-value & A & $B$ & $\mathrm{t}$-value & $\mathrm{A}$ & $\mathrm{B}$ & t-value & $\mathrm{A}$ & $B$ & t-value \\
\hline Collaborative leadership & 4.13 & 2.25 & $19.345^{*}$ & 4.41 & 2.34 & $10.445^{*}$ & 4.40 & 2.20 & $9.314^{*}$ & 4.21 & 2.26 & $23.870^{*}$ \\
\hline Communication skills & 4.21 & 2.15 & $20.753^{*}$ & 4.76 & 2.59 & $9.771^{*}$ & 4.65 & 2.20 & $9.969^{*}$ & 4.36 & 2.23 & $24.897^{*}$ \\
\hline Empathy skills & 4.19 & 2.23 & $19.806^{*}$ & 4.48 & 2.41 & $10.445^{*}$ & 4.30 & 2.10 & $8.223^{*}$ & 4.26 & 2.25 & $23.911^{*}$ \\
\hline Conflict solving skills & 4.22 & 2.21 & $20.882^{*}$ & 4.45 & 2.24 & $11.727^{*}$ & 4.35 & 2.55 & $5.753^{*}$ & 4.28 & 2.26 & $23.921^{*}$ \\
\hline Decision making skills & 4.02 & 2.20 & $17.133^{*}$ & 4.48 & 2.24 & $11.797^{*}$ & 4.05 & 2.55 & $4.807^{*}$ & 4.11 & 2.25 & $20.367^{*}$ \\
\hline Problem solving skills & 4.05 & 2.15 & $18.997^{*}$ & 4.52 & 2.24 & $11.156^{*}$ & 4.35 & 2.40 & $6.622^{*}$ & 4.18 & 2.19 & $22.724^{*}$ \\
\hline $\begin{array}{l}\text { Understanding the roles of other } \\
\text { professionals }\end{array}$ & 4.06 & 2.18 & $19.345^{*}$ & 4.31 & 2.38 & $8.505^{*}$ & 4.55 & 2.55 & $6.686^{*}$ & 4.17 & 2.26 & $21.937^{*}$ \\
\hline $\begin{array}{l}\text { Understanding their own roles } \\
\text { within the collaborative practice }\end{array}$ & 4.00 & 2.37 & $14.761^{*}$ & 4.48 & 2.62 & $8.912^{*}$ & 4.50 & 2.70 & $5.604^{*}$ & 4.15 & 2.46 & $18.001^{*}$ \\
\hline Legal ethical decision-making skills & 4.08 & 2.27 & $17.719^{*}$ & 4.38 & 2.62 & $6.620^{*}$ & 4.20 & 2.60 & $5.812^{*}$ & 4.15 & 2.38 & $19.314^{*}$ \\
\hline
\end{tabular}

A: The level of importance of IPE competences, B: The present competence levels of their students. ${ }^{*} p=0.000$.

\begin{tabular}{|c|c|c|c|}
\hline & Competency & Needs assessment scores & Ranks \\
\hline 1 & Collaborative leadership & 8.701 & 5 \\
\hline 2 & Communication skills & 10.210 & 1 \\
\hline 3 & Empathy skills & 9.110 & 4 \\
\hline 4 & Conflict solving skills & 10.114 & 2 \\
\hline 5 & Decision making skills & 8.493 & 7 \\
\hline 6 & Problem solving skills & 9.319 & 3 \\
\hline 7 & Understanding the roles of other professionals & 8.624 & 6 \\
\hline 8 & Understanding their own roles within the collaborative practice & 7.962 & 9 \\
\hline 9 & Legal ethical decision-making skills & 8.109 & 8 \\
\hline
\end{tabular}

well as the level of importance of IPE competences (Table 5).

\section{Analysis on the order of priority for IPE education programs using the Borich coefficient}

The Borich coefficient was calculated to identify the order of priority among the nine competences to develop an IPE program for students. The order of priority was communication skills (10.210), conflict solving skills (10.114), problem solving skills (9.319), empathy skills (9.110), and collaborative leadership (8.624) (Table 6).

\section{Discussion}

This study compared and analyzed the perceptions of IPE from the faculty members in the schools of medicine, nursing, and pharmacy, and analyzed the differences in their perceptions on the level of importance of IPE competences and the present competence levels of their students in order to validate the implementation of IPE and develop a faculty development program and a student program. The summary and discussions on the results are as follows. In terms of the perception of IPE of the faculty members in the schools of medicine, nursing, and pharmacy, $14.8 \%$ responded that they knew about IPE, which shows 
a low perception of IPE. There were a significantly higher number of faculty members in the school of medicine who responded that they did not know about IPE. Participants of $95.8 \%$ responded that they did not have any experience with IPE, and most did not have experience in learning about IPE. However, 95.8\% responded that they had a positive perception on the importance of the IPE program. The results are similar to the results of prior studies in Korea that used a sample of doctors and nurses [10,11], reconfirming the fact that there is still insufficient perception and experience in IPE in the Korean healthcare related education curriculum. This may be because most of the professors are more familiar with uni-professional environments and unfamiliar with a team-based approach like IPE [20]. Furthermore, they may have insufficient experiences with IPE as they were educated before the importance of IPE was established [21]. Therefore, most of the faculty members are not prepared to teach students based on IPE programs [22]. Faculty members who reported prior experience in IPE, may have more positive perceptions toward IPE, and less resistance toward the implementation of an education curriculum with IPE [23-25]. Therefore, it is necessary for universities to develop a systematic faculty development program to enhance the interests of the faculty in IPE and provide opportunities for them to experience IPE. This will be a core factor in successfully implementing the IPE program [26,27].

There were significant differences in the perceptions of the importance of IPE, effectiveness of IPE, and support towards IPE from faculty members in the schools of medicine, nursing, and pharmacy. The perceptions of the faculty in the school of nursing was relatively higher, whereas the faculty in the school of medicine had the lowest perceptions. These results are identical to those of prior studies $[13,23,28]$. The medical system historically had a strict hierarchy among the healthcare professionals [29], and such a medical environment may have affected the low perception levels of the faculty of medicine on the need of collective practice with professionals in other areas. In addition, the low perceptions on IPE of faculty members in the school of medicine may also affect the perceptions of their students on IPE. There were prior studies that reported that students in the school of medicine were more skeptical of the usefulness of IPE programs than the students in other healthcare fields and have less passion about participation in the program [30,31]. The results of this study showed that the perception on IPE was the highest from the faculty members of the school of nursing, like other prior studies. This supports the fact that they have an in-depth perception on the importance of IPE in comparison to the faculty members in other healthcare fields and are passionate about participating in IPE programs $[13,28]$. Therefore, as the differences in perceptions on IPE among the faculty of various healthcare fields may lead to difficulties in planning IPE programs, it is necessary for universities to provide measures that decrease the differences. In other words, it is important to develop programs or an education curriculum and implement interventions in a team with interprofessional faculty to match the concept of IPE [25]. This will allow for faculty members to enhance their understandings on other fields, experience teamwork, and experience the effectiveness of IPE firsthand.

After analyzing the level of importance of IPE competences of the faculty members, and the present competence levels of their students, it was shown that the faculty members perceive present competence levels of their students to be lower than the level of importance of IPE competences, regardless of their majors. As faculty members are generally evaluators, they are strict in evaluating students, which may have affected the 
relatively low competence levels of students. In particular, faculty in the school of medicine had lower perceptions on the levels of the students, as well as the level of importance of IPE competences than the faculty members in the schools of nursing and pharmacy. A number of prior studies showed that the faculty members in the school of medicine had the lowest perception of the importance of IPE compared to other faculty members [13,23,28], which may have led to a low evaluation on the importance of IPE competences. In addition, the results of analyzing the differences in the levels of importance of IPE competences and the current competence levels of the students showed that there is the greatest difference in communication skills among professionals. This means that the faculty should prioritize communication skills among professionals for IPE programs. A Comparative Analysis of Competences and Frameworks in Interprofessional Education done by the United States, Canada, Britain, and Australia showed that communication among professionals is an important domain of competences in all countries [32]. Many healthcare professionals experience lack of communication and conflict due to the mutual exclusivity of healthcare areas and the hierarchical clinical environment [33]. Many healthcare professionals including doctors and nurses cited ineffective communication, lack of interpersonal skills, and negative attitudes towards others as the common causes of conflict [34]. As the faculty members, who were the participants of this study, had experienced such conflict in the past, they may have been inclined to point out communication between professionals as the most important competence. Therefore, education with goals of improving communication skills among professionals should be put of utmost importance when developing an IPE program for students in the future.

Although the participants of the study were faculty members in the schools of medicine, nursing, and pharmacy, it is necessary to perform additional studies with more faculty members to generalize the results, as there were relatively less faculty members in the schools of nursing and pharmacy in comparison to those in the school of medicine. Furthermore, IPE programs have numerous obstacles as many majors are involved [35]. Therefore, it is necessary to identify the fundamental obstacles; future studies should focus on the policies at a national level to overcome the obstacles. In addition, there is a need to develop and implement a faculty development program to incorporate IPE programs and analyze their effects. If the faculty development programs lead to active exchanges between professionals in various healthcare fields, and greater mutual understanding, it will be possible to implement IPE programs more widely. This study is significant as it identified healthcare faculty members' perceptions of IPE, to provide basic data that can help us understand the directions in which IPE programs can be developed for students and the faculty in the future.

\section{ORCID:}

So Jung Yune: https://orcid.org/0000-0002-2567-0444;

Kwi Hwa Park: https://orcid.org/0000-0002-0008-2400;

Yul Ha Min: https://orcid.org/0000-0002-1657-8582;

Eunhee Ji: https://orcid.org/0000-0001-8558-1032

Acknowledgements: None.

Funding: This work was supported by the National Research Foundation of Korea Grant funded by the Korean Government (NRF-2017S1A5A2A01025837).

Conflicts of interest: No potential conflict of interest relevant to this article was reported.

Author contributions: SJY: drafting the article, data collection, data analysis and interpretation; KHP: conception or design of the work, data collection, data 
analysis and interpretation, critical revision of the article, and final approval of the version to be published; YHM: data collection, data analysis and interpretation; EHJ: data collection, data analysis and interpretation.

\section{References}

1. Aston SJ, Rheault W, Arenson C, et al. Interprofessional education: a review and analysis of programs from three academic health centers. Acad Med. 2012;87(7):949955.

2. World Health Organization. Framework for action on interprofessional education and collaborative practice. Geneva: World Health Organization; 2010.

3. Oandasan I, Reeves S. Key elements for interprofessional education. Part 1: the learner, the educator and the learning context. J Interprof Care. 2005;19 Suppl 1:2138.

4. Centre for the Advancement of Interprofessional Education. A definition of Interprofessional Education. https://www.caipe.org/resource/CAIPE-Statement-of-Purp ose-2016.pdf. Accessed December 20, 2019.

5. Zorek J, Raehl C. Interprofessional education accreditation standards in the USA: a comparative analysis. J Interprof Care. 2013;27(2):123-130.

6. West C, Graham L, Palmer RT, et al. Implementation of interprofessional education (IPE) in 16 U.S. medical schools: common practices, barriers and facilitators. J Interprof Educ Pract. 2016;4:41-49.

7. Blue AV, Zoller J, Stratton TD, Elam CL, Gilbert J. Interprofessional education in US medical schools. J Interprof Care. 2010;24(2):204-206.

8. Kwon NR, Cho E. A systematic review on the vocational pharmacy education and pharmacists' role in the Singapore's healthcare system. Korean J Clin Pharm. 2015;25(3):187-199.
9. Yoo BK. Comparison of pharmacist and other healthcare professionals license examination in Korea. Korean J Clin Pharm. 2013;23(1):71-76.

10. Lee YH, Ahn D, Moon J, Han K. Perception of interprofessional conflicts and interprofessional education by doctors and nurses. Korean J Med Educ. 2014;26(4): 257-264.

11. Kim KH, Hwang E, Shin S. Current status and future direction of interprofessional education in nursing education. Korean Med Educ Rev. 2017;19(1):18-24.

12. Curran VR, Sharpe D, Flynn K, Button P. A longitudinal study of the effect of an interprofessional education curriculum on student satisfaction and attitudes towards interprofessional teamwork and education. J Interprof Care. 2010;24(1):41-52.

13. Gary JC, Gosselin K, Bentley R. Health science center faculty attitudes towards interprofessional education and teamwork. J Interprof Care. 2018;32(2):231-234.

14. Baek SY, Yun SJ, Kam B, Lee SY, Woo JS, Im SJ. The role of the teaching hospital in the effective clerkship. Korean Med Educ Rev. 2015;17(1):5-9.

15. Eom MR. Educational needs analysis of instructional designers in Korea for competency development. J Vocat Educ Train. 2009;12(1):1-23.

16. Parsell G, Bligh J. The development of a questionnaire to assess the readiness of health care students for interprofessional learning (RIPLS). Med Educ. 1999;33(2): 95-100.

17. McFadyen AK, Webster V, Strachan K, Figgins E, Brown $\mathrm{H}$, McKechnie J. The readiness for Interprofessional Learning Scale: a possible more stable sub-scale model for the original version of RIPLS. J Interprof Care. 2005; 19(6):595-603.

18. Canadian Interprofessional Health Collaborative. A national interprofessional competency framework. Vancouver: University of British Columbia; 2010.

19. Borich GD. A needs assessment model for conducting 
follow-up studies. J Teach Educ. 1980;31(1):39-42.

20. Casa-Levine C. The value of interprofessional education: assessing the attitudes of dental hygiene administrators and faculty. J Dent Hyg. 2017;91(6):49-58.

21. Becker KL, Hanyok LA, Walton-Moss B. The turf and baggage of nursing and medicine: moving forward to achieve success in interprofessional education. J Nurse Pract. 2014;10(4):240-244.

22. Sargeant J, Hill T, Breau L. Development and testing of a scale to assess interprofessional education (IPE) facilitation skills. J Contin Educ Health Prof. 2010;30(2): 126-131.

23. Curran VR, Sharpe D, Forristall J. Attitudes of health sciences faculty members towards interprofessional teamwork and education. Med Educ. 2007;41(9):892896.

24. Vernon MM, Moore NM, Cummins LA, et al. respiratory therapy faculty knowledge of and attitudes toward interprofessional education. Respir Care. 2017; 62(7):873-881.

25. Loversidge J, Demb A. Faculty perceptions of key factors in interprofessional education. J Interprof Care. 2015; 29(4):298-304.

26. Simmons B, Oandasan I, Soklaradis S, et al. Evaluating the effectiveness of an interprofessional education faculty development course: the transfer of interprofessional learning to the academic and clinical practice setting. J Interprof Care. 2011 1;25(2):156-157.

27. Hall LW, Zierler BK. Interprofessional education and practice guide no. 1 : developing faculty to effectively facilitate interprofessional education. J Interprof Care. 2015;29(1):3-7.
28. Khajehghyasi RV, Jafari SE, Shahbaznejad L. A survey of the perception of interprofessional education among faculty members of Mazandaran University of Medical Sciences. Strides Dev Med Educ. 2017;14(2):e64086.

29. Buring SM, Bhushan A, Brazeau G, Conway S, Hansen L, Westberg S. Keys to successful implementation of interprofessional education: learning location, faculty development, and curricular themes. Am J Pharm Educ. 2009;73(4):60.

30. Ponzer S, Hylin U, Kusoffsky A, et al. Interprofessional training in the context of clinical practice: goals and students' perceptions on clinical education wards. Med Educ. 2004;38(7):727-736.

31. Van Winkle LJ, Bjork BC, et al. Interprofessional workshop to improve mutual understanding between pharmacy and medical students. Am J Pharm Educ. 2012;76(8):150.

32. Thistlethwaite JE, Forman D, Matthews LR, Rogers GD, Steketee C, Yassine T. Competencies and frameworks in interprofessional education: a comparative analysis. Acad Med. 2014;89(6):869-875

33. Park KO. Nurses' experience of health communication with doctors in the clinical fields. J Korean Acad Nurs Adm. 2015;21(1):53-63.

34. Lee B, Kim M. An exploratory investigation on conflicts between physicians and nurses: types, causes, and asymmetry. Korean J Ind Organ Psychol. 2012;25(1): $1-25$.

35. Christofilos V, DeMatteo D, Penciner R. Outcomes of commitment to change statements after an interprofessional faculty development program. J Interprof Care. 2015;29(3):273-275. 